\title{
Research Paper \\ Green Strategy Practices Using the (Kao) Model In the Oil Products Distribution Company of Nineveh: A Case Study
}

Journal of

TANMIYAT ALRAFIDAIN

\section{(TANRA)}

A scientific, quarterly, international, open access, and peer-reviewed journal

Vol. 39, No. 126

June 2020

(C) University of Mosul |

College of Administration and

Economics, Mosul, Iraq.

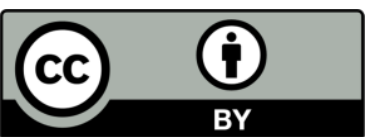

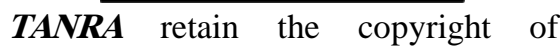
published articles, which is released under a "Creative Commons Attribution License for CC-BY-4.0" enabling the unrestricted use, distribution, and reproduction of an article in any medium, provided that the original work is properly cited.

Citation: Hala F. D. AL Mullah Tohi. (2020). "Green Strategy Practices Using the (Kao) Model In the Oil Products Distribution Company of Nineveh: A Case Study". TANMIYAT $\boldsymbol{A L}$ RAFIDAIN, 39 (126), 21 -39, https://doi.org/10.33899/tanra.20 20.165650

P-ISSN: 1609-591X e-ISSN: 2664-276X tanmiyat.mosuljournals.com

\section{Hala F. D. AL Mullah Tohi ${ }^{1}$ \\ ${ }^{1}$ University of Mosul}

Corresponding author: Hala F. D. AL Mullah Tohi. Presidency University of Mosul. University of Mosul, halafazea@gmail.com.

DOI: https://doi.org/10.33899/tanra.2020.165650

Article History: Received: 12/12/2019; Revised: 17/2/2020; Accepted: 15/4/2020; Published: 1/6/2020.

\section{Abstract}

The study aims to define the green strategy and identify the level of its application in the investigated organization through its indicating practices. To achieve that aim, the Oil Products Distribution Company in Nineveh was chosen as a field for the study. A questionnaire form was used as the main tool in collecting data. The questionnaire was distributed among a sample of (103) employees in the investigated organization. Based on the results of statistical analysis, using descriptive measures and Friedman Test, a set of conclusions were presented. The most important of these conclusions was that there is an agreement that green strategy practices are present in the investigated company with a level that is distinctive from other practices. In order to achieve the aim of the study, a number of recommendations were set fourth including the necessity of increasing the actual management attention to areas that support environmental orientation, especially through the green strategy and its indicating practices in the investigated organization.

\section{Keywords}

Green Strategy, Case Study. 


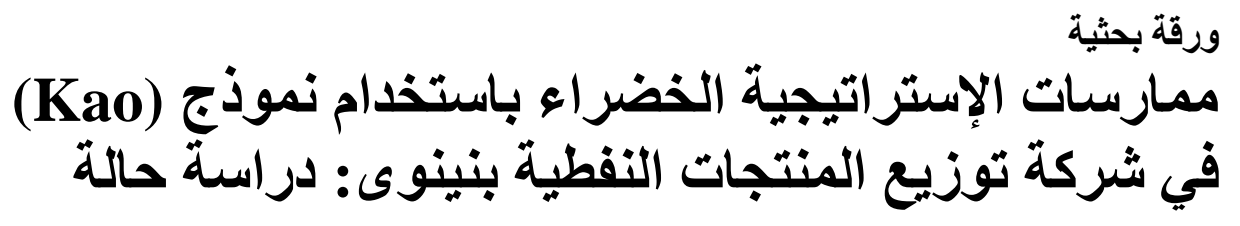

حلا فازع داغر الملا توحي 1

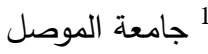

المؤلف المراسل حلا فازع داغر الملا توحي ، رئاسة جامعة الموصل، جامعة الموصل، الموصل، العراق، halafazea@gmail.com.

DOI: https://doi.org/10.33899/tanra.2020.165650

تاريخ المقالة: الاستلام: 2019/12/12؛ التعديل والتنقيح: 2020/2/17؛ القبول: 2020/4/15؛ النشر : $.2020 / 6 / 1$

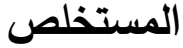

يهذف البحث إلى تحدي الإستراتيجية الخضراء وتشخيص مستوى تطبيقها في المنظمة المبحوثة

عبر المدارسات الدالة عليها، وبغية تحقيق ذلك تم اختيار شركة توزيع المنتجات النفطية في نينوى ميداناً

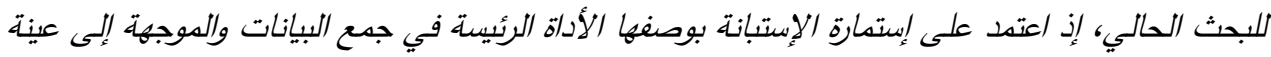

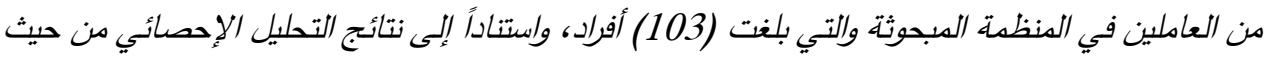
الدقاييس الوصفية و(Friedman Test) تم تقديم مجوعة من الاستتاجات، أهدها وجود حالة من الإتغاق

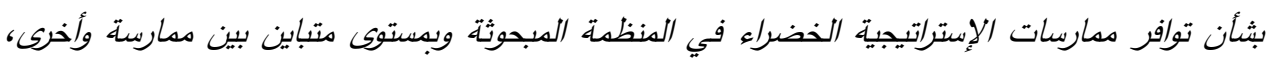

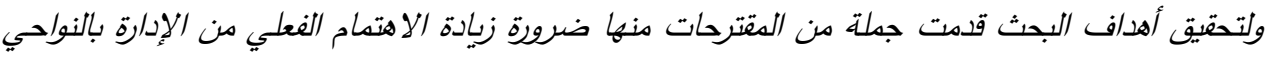
الداعة للتوجهات البيئية وتحديداً عبر الإستراتيجية الخضراء والدمارسات الدالة عليها في الدنظمة الدبحوثة.

\section{الكلمات الرئيسة}

الإستراتيجية الخضراء ، دراسة حالة.

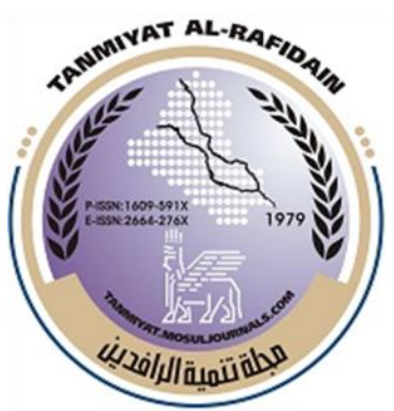

\section{هبلة}

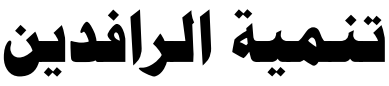

رولة دولية، مفتوحة الوصول، محكمة.

$$
\text { المجلد (39)، العدد (126)، }
$$
حزيران 2020

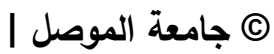
كلية الإدارة والاقتصاد، الدوصل، العراق.

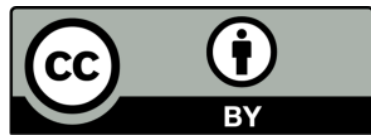

تحتفظ (TANRA) بحقوق الطبع والنشر للمقالات المنشورة، والتي يتم إصدارها بموجب ترخيص \lrcorner (Creative Commons Attribution) (CC-BY-4.0) الذي يتيح الاستخدام، والتوزيع،

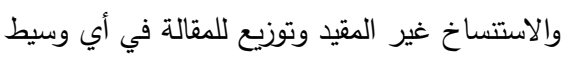
نقل، بشرط اقتباس العمل الأصلي بثكل صحيح.

الاقتباس: حلا فازع داغر الملا نوحي

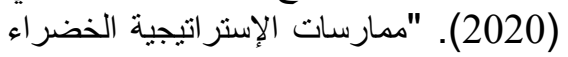
باستخدام نموذج (Kao) في شركة توزيع الأنيع المنتجات النفطية بنينوى: دراسة حالة حالة

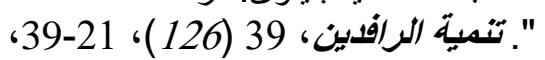
https://doi.org/10.33899/tanra.20 20.165650

P-ISSN: 1609-591X e-ISSN: 2664-276X tanmiyat.mosuljournals.com 
ازدادت التحديات التي تتعرض لها المنظمات وخاصة عندما تكون أمام العديد من الخيارات، وعلى نحو يضعها أمام سلم الاختيارات، وفي ذلك نقطة تحدٍ وعامل ولوج نحو المفاضلة بين ما هو قائم ومعمول

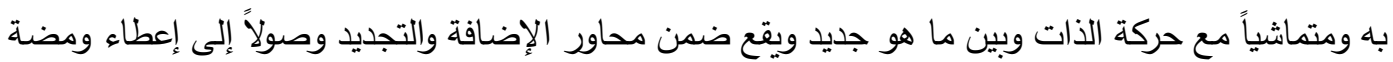

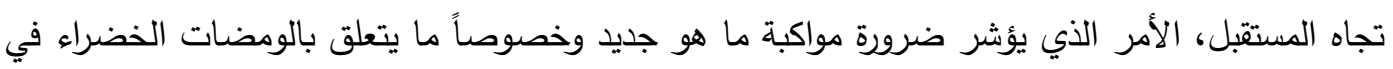
مجالات العمل التظظيمي ومنها الإستراتيجي، وبهذا تبرز أهمية البحث الحالي من سعيه الجيه الجاد إلى تحديد

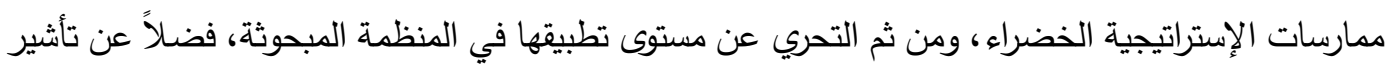

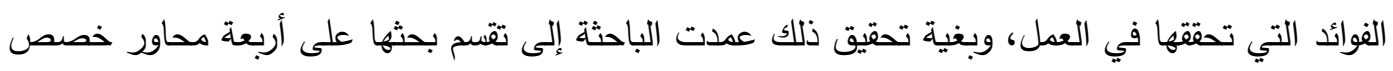

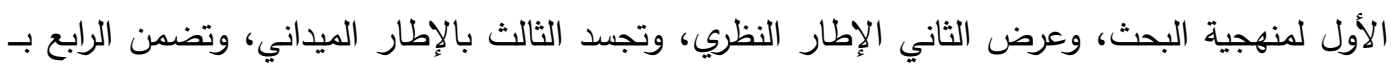

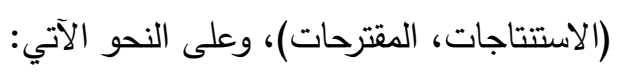

\section{المحور الأول: منهجية البحث}

تمهيداً للإطار الميداني يعرض المحور الأول منهجية البحث في ضوء تأشير مشكلته وأهميته وأهدافه

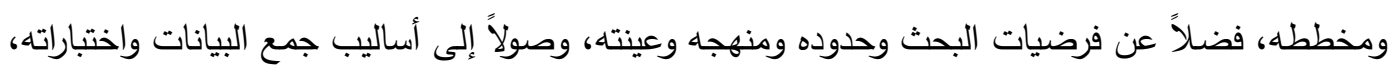

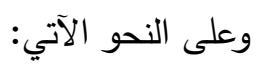

\section{أولاً- مشكلة البحث}

قادت التطورات البيئية إلى بروز جملة من التحديات ذات الأثر البالغ وعلى نحو خاص في المنظومة الصناعية ومنها في شركة توزيع المنتجات النفطية في نينوى متمثلة بضرورة مواكبة الممارسة الخضراء في

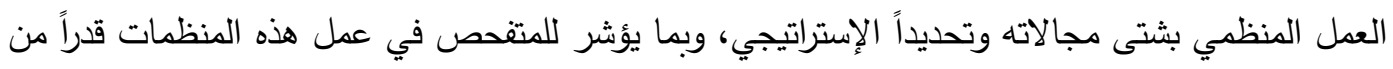
الجدية في معالجة حالات التلوث ومواكبة المفهوم الأخضر الذي بات مطلب الجميع، لما يحققه من فوائد

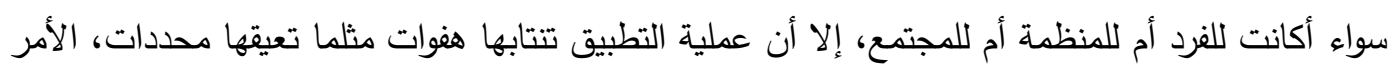

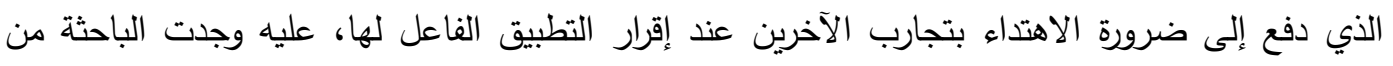
موضوع ممارسات الإستراتيجية الخضراء عبر طروحات (Kao, et al., 2008) منطلقاً لتحديد ما هو سائد في هذا المجال، ومن ثم بيان مستوى الأخذ به على مستوى البيئة العراقية وتحديداً في المنظمة المبحوثة، وعليه تحددت مشكلة البحث الحالي في التساؤلات الآتية: 1. ما مستوى تبني (توافر) ممارسات الإستراتيجية الخضراء في المنظمة المبحوثة، وبما يجسد مستوى فئاتي الفاعلية والقصور فيها ؟ مأبن 2. هل هناك تباين في مستوى تطبيق ممارسات الإستراتيجية الخضراء في المنظمة المبحوثة، وبما يعكس

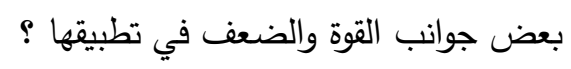




$$
\text { ثانياً- أهمية البحث }
$$

1. الأهدية النظريـة: تحددت عن طريق الإســـهامات التي يمكن أن يحققها البحث في عرض الإطـار

$$
\text { النظري عبر الإفادة من طروحات المختصين في هذا المجال. }
$$

2. الأهمية الميدانية: تمركزت في سـعيه الجاد نحو مسـاعدة المنظمة المبحوثة من معالجة ظاهرة التلوث

ومواكبة المفهوم الأخضر في مجال الإستراتجية الخضراء عبر الممارسات الدالة عليها.

$$
\begin{aligned}
& \text { ثالثاً - أهداف البحث } \\
& \text { تلخصت أهداف البحث في الآتي: } \\
& \text { 1. تقديم تغطية نظرية لموضوع البحث (ممارسات الإستراتيجية الخضراء). } \\
& \text { 2. تأشير مستوى تطبيق ممارسات الإستراتيجية الخضراء في المنظمة المبحوثة. }
\end{aligned}
$$

3. عرض عدد من المقترحات التي من شأنها معالجة بعض حالات القصور في تطبيق ممارسات

الإستراتيجية الخضراء في المنظمة المبحوثة، وبما يسهم في تعزيز مستوى تطبيقها.

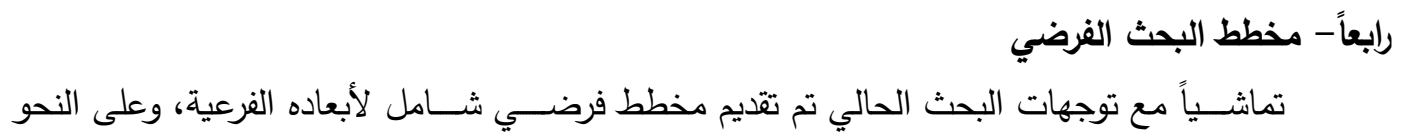
الآتي: 

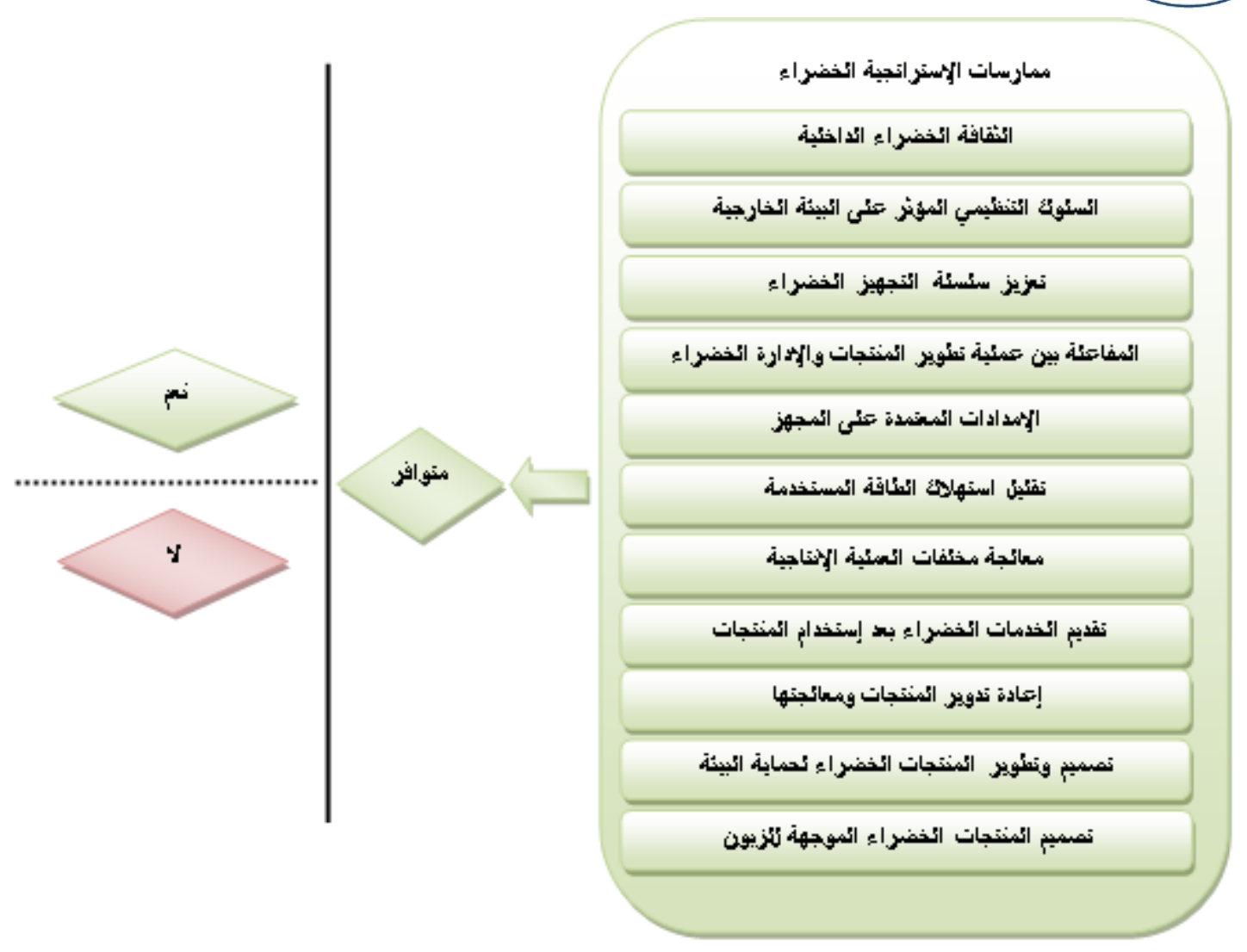

1 الثكل 1

مخطط البحث الفرضي

المصدر: الثكل من إعداد الباحثة.

خامساً- فرضيات البحث

تمثلت فرضيات البحث الحالي في الآتي:

الفرضية الرئيسة الأولى: لا تتوافر ممارسات الإستراتيجية الخضراء في المنظمة المبحوثة. الفرضية الرئيسة الثانية: لا يتباين مستوى تطبيق ممارسات الإستراتجية الخضراء في المنظمة المبحوثة.

سادساً- مجتمع البحث وعينته

تمثل مجتمع البحث الحالي في شركة توزيع المنتجات النفطية بنينوى، وأما عينة البحث بلغت (103) أفراد من مختلف المستويات الإدارية بوصفهم من يقوم بتتفيذ هذه الممارسات في المنظمة المبحوثة.

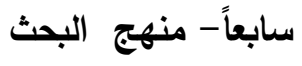

اعتمدت الباحثة في تغطية البحث الحالي على منهج دراسـة الحالة (Case Study) بوصـفه من مناهج البحث الوصفية والتفصيلية الذي يعتمد على تجميع البيانات وتبويبها وتحليلها وتفسيرها للمشكلة قيد 
الدراسـة، فضــلاً عن إمكانية إعتماد أكثر من أداة بحث في المنظمة المبحوثة، وبما يسـهم في تحقيق أهداف

$$
\text { البحث الحالي. }
$$

$$
\text { ثامناً - حدود البحث }
$$

1. الحدود الزمنية : تم إنجاز البحث خلال الفترة من (2019/7/1) وحتى (2019/12/12). 2. الحدود المكانية: تم إجراء البحث في شركة توزيع المنتجات النفطية بنينوى.

3. الحدود البشرية: عينة من العاملين في شركة توزيع المنتجات النفطية بنينوى.

4. الحدود العلمية: اقتصر البحث على متغير الإستراتيجية الخضراء من خلال ممارساتها. تاسعاً - أساليب جمع البيانات

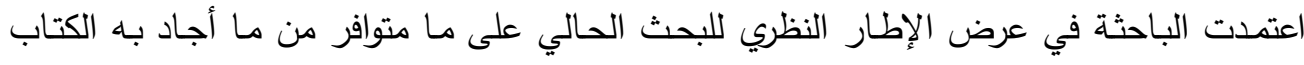

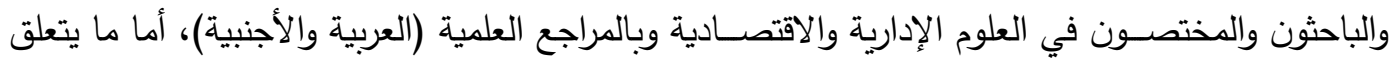

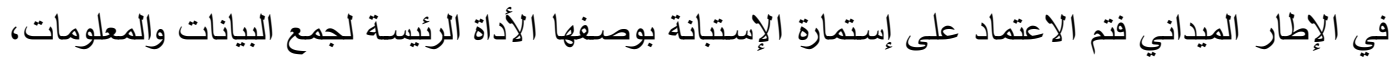

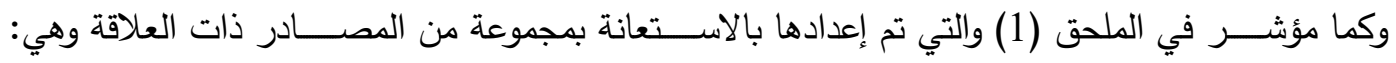

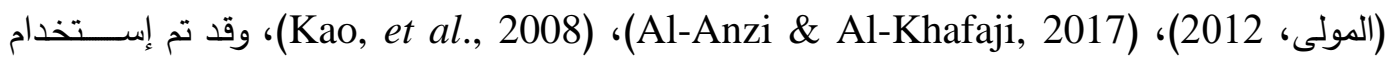

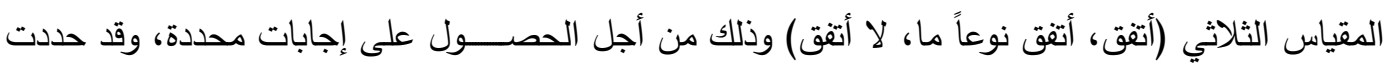

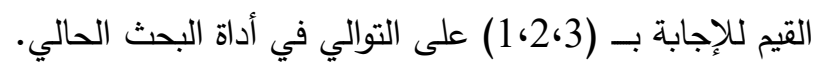

عاشراً - أساليب التحليل وإلمعالجة الإحصائية أعتمد في إتمام الإطار الميداني للبحث الحالي على العديد من الأساليب الإحصائية، إذ تم إستخراج

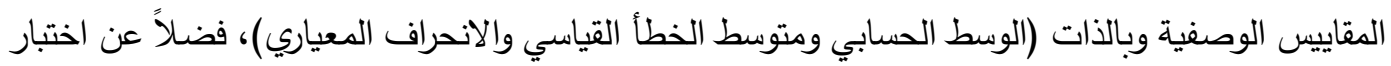
لتحديد مدى وجود فروق معنوية ذات دلالة إحصائية بين الممارسات في المنظمة المبحوثة.

الحادي عشر - اختبار أداة البحث

خضعت أداة البحث الحالي (إستمارة الإستبانة) إلى مجموعة اختبارات وعلى النحو الآتي:

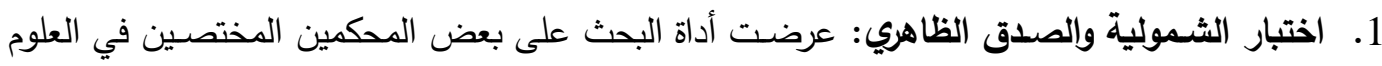
الإدارية والاقتصادية، وكما مؤشر في الملحق (2)، وفي ضوء ملاحظاتهم ومقترحاتهم تم تعديل فقرات

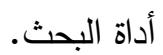
2. الحيادية: ســـت الباحثة عند توزيع أداة البحث إلى عدم التأثير في إجابات الأفراد المبحوثين، فضــلاً عن إعطائهم الوقت الكافي والحرية في التعبير عن آرائهم تجاه متغيرات وفقرات أداة البحث. المحور الثاني- الإطار النظري النمان 
يمكن تقديم تغطية نظرية لموضوع البحث الحالي (ممارسات الإستراتيجية الخضراء)، عبر توظيف ما أجاد به الفكر الإداري، وبما يمكن من إثراء هذا الموضوع وعلى قدر الإمكان، وكالأتي:

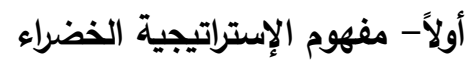

تؤكد معظم الدراسات والبحوث حول الإدارة الإستراتيجية وجود ضعف في تغطية جوانب هذاء التخصص، إذ يكون التركيز بالدرجة القصوى نحو ما متداول وشائع وبالذات ما يتعلق بالمراحل الإستراتيجية

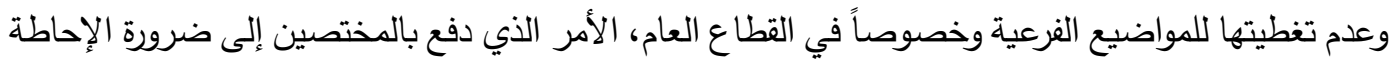
الواسعة بأبعاد هذا الموضوع، فتتفيذ الإستراتيجية في القطاع العام مهم، وذلك لكونها تعمل على تحقيق القيمة للمواطن، ومن هنا فالتوجهات الحديثة أفرزت مجموعة من المعطيات وجهت القائمين نحو الإهتمام بالبنية التحتية ومعالجة النفايات وإدارة الطاقة وتقعيل وسائل الدعم الثقافي والعلاقات العامة وكيفية الإهتمام بالبيئة،

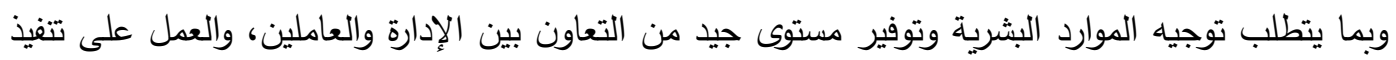

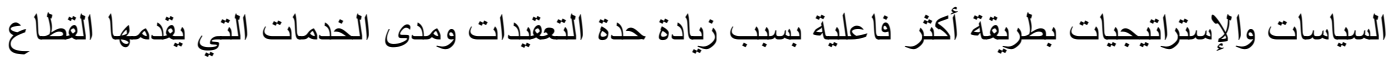
العام، وبما يساعد في كسب الدعم والرضا وتحقيق المصلحة العامة (4-4) (Genc, 2017, 3)، عليه ازدادت التوجهات في القطاع العام وبالذات في قطاع النفط بإعادة النظر في مضامين الإدارة الإستراتيجية وإستبدالها

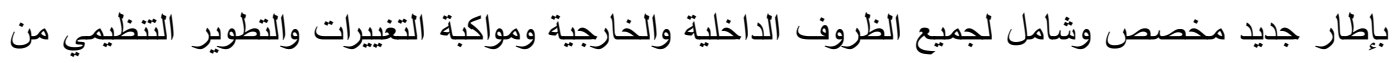
خلال الممارسات الخضراء في الأداء التنظيمي (Ayoubi et al., 2017,2). وقد عرفت الإدارة الإستراتيجية بتعريفات متعددة وكما أشار إليها الكتاب والباحثين والمختصين في الاهي العلوم الإدارية والاقتصادية ومنهم (Muiru, 2011, 6)، (Mainardes, et al., 2014, 48)،

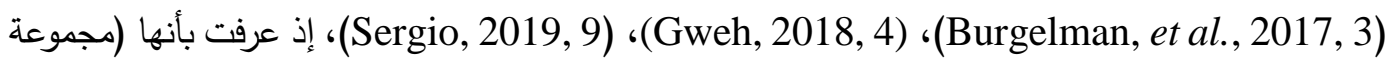
من الممارسات والعمليات التي تمكن المنظمة من تحقيق أهدافها في البقاء والنمو وتحقيق الميزة التتافسية، وهذا يكون من خلال تشخيص جوانب القوة و الضعف الداخلية والفرص والتهديدات الخارجية).

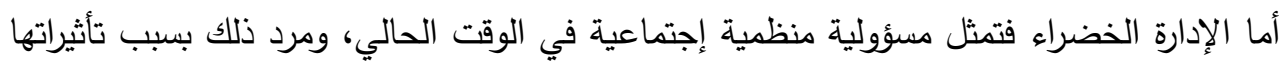

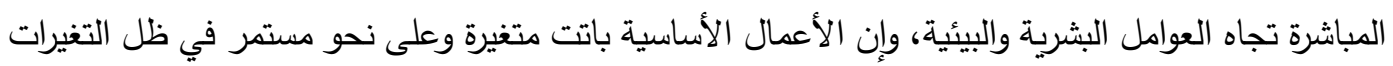
الحاصلة، الأمر الذي وضع هذه المنظمات أمام عدد من التحديات تمثلت بالسعي نحو الاهتمام بمستقبل المجتمع والبيئة التي تعمل فيها المنظمة، ومن هذا المنطلق يؤشر مدى زيادة الاهتمام بدراسة الإدارة الخضراء والأداء البيئي للمنظمات والتركيز على تقليل مستوى تلوث البيئة ومعالجة المواد والنفايات في العمل، وبدأ

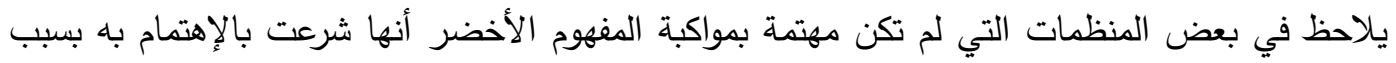

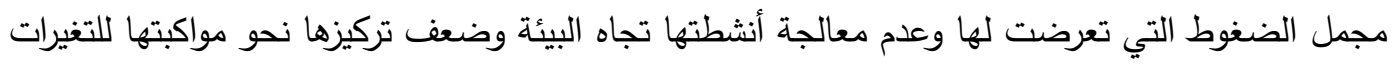
والتطورات في مجال أنشطة البيئة الخضراء (Sawan, et al, 2013, 5695)، كما إن الأعمال الخضراء

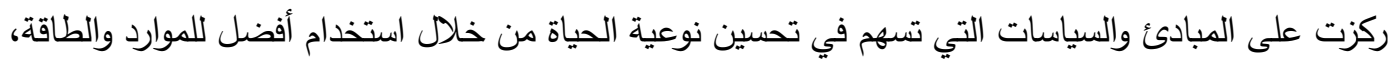
فضلاً عن إعادة التدوير وتقليل مستويات التلوث (Karagülle, 2012, 457). 
ويمكن عرض الجدول 1 الذي يوضح توجهاب بعض الكتاب والباحثين والتي تمكنت الباحثة من الإطلاع عليها بخصوص تعريف الإستراتيجية الخضراء وبحسب التسلسل الزمني، وعلى النحو الآتي:

جدول (1): تعريفات الإستراتيجية الخضراء عند عدد من الكتاب والباحثين وبحسب التسلسل الزمني لها

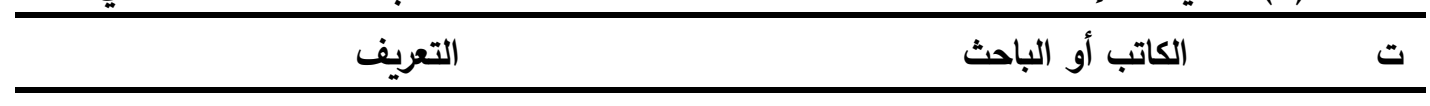

تتركز الإستراتيجية الخضراء في تفعيل القدرات الداعمة

1.

التنافسية.

تتمحور الإستراتيجية الخضراء حول الإلتزام القوي بالمسؤولية البيئية في ممارسة كافة الأنشطة.

(Saeed, 2013, 141)

مجموعة من الأنثطة التي تمكن الإدارة من اتخاذ القرارات ذات التأثير الإيجابي نحو البيئة.

(Padash, et al, 2015, 260) $\quad .3$

عبارة عن الإستراتيجيات التي تهدف إلى تعزيز المجالات

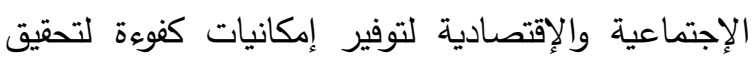

(Al-Abedi \& Al-Jubouri, 2017, 6)

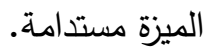

المصدر: الجدول من إعداد الباحثة بالإعتماد على المصادر أعلاه.

مما سبق يمكن تأشير مدى اختلاف توجهات الكتاب والباحثين بخصوص مفهوم الإستراتيجية الخضراء، ومرد ذلك لاختلاف أهداف دراساتهم، فضلاً عن البيئة التي طبقت دراستهم فيها، وصولاً إلى الفترة الزمنية للدراسة، لذلك فإن البعض ركز على المسؤولية البيئية، والآخر اهتم بالقرارات الداعمة للتوجهات البيئية،

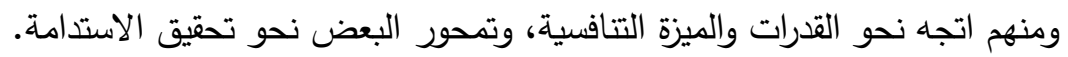

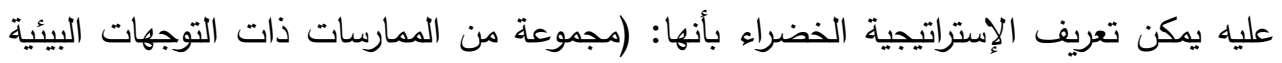
الهادفة إلى تعزيز مسؤولياتها في الحد من مخاطرها البيئية، وبما يمكنها من تعزيز مستويات النمو الموجه بالإستدامة).

ثانياً- أهمية الإستراتيجية الخضراء وخصائصها إن معظم المنظمات في الوقت الحاضر باتت قدراتها التتافسية متداخلة وعلى نحو بالغ مع أنشطتها

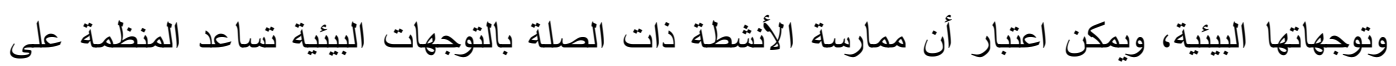
تطوير المنتجات الجديدة والدخول إلى الأسواق واعتماد التقنيات المتطورة، والتركيز على الإستراتيجية الخضراء داء التهاء تمكن من مساعدة الإدارات على تخفيض إجمالي التكاليف في العمل التنظيمي، وبما يسهم في زيادة إيراداتها،

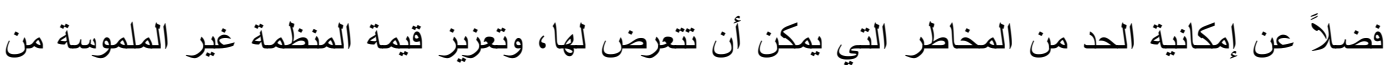


حيث السمعة والعلامة التجارية، وصولاً إلى تقليل مستويات الضغوط التي يمكن أن تواجهها بسبب زيادة

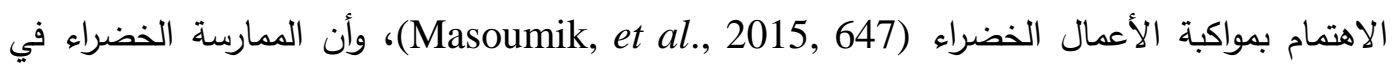
إستراتيجية المنظمة يمكنها من تحقيق المزايا التتافسية بدءاً بالكلفة المنخفضة ومرد ذلك الاستخدام الكفوء في

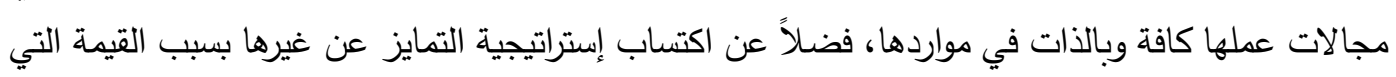
تحققها تجاه البيئة وتوجهاتها في تقديم كل ما هو داعم لها، وبما يحقق الزيادة في القيمة السوقية ويعزز

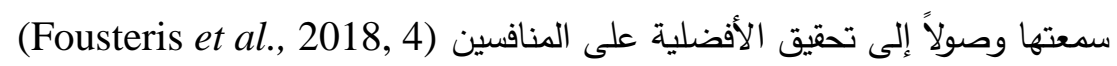
كما أن المنظمات التي تتمكن من وضع إستراتيجية خضراء لأعمالها وأنشطتها يمكن أن تتصف الأنف

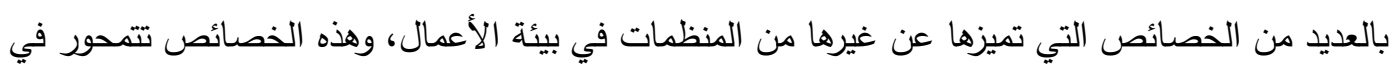

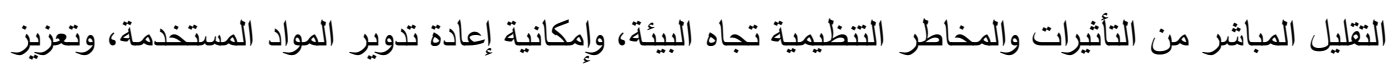

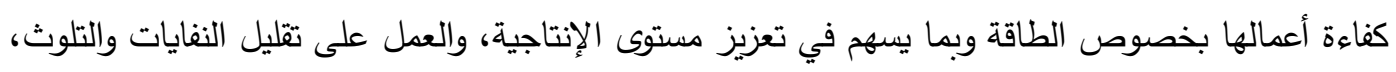

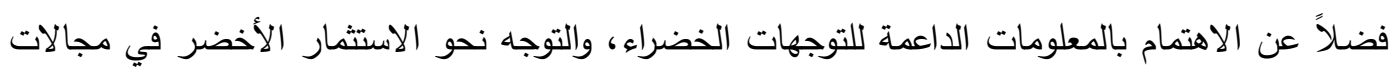
العمل كافة (Loknath \& Azeem 2017, 693-694)). مما تقدم نلاحظ أن الحركة الديناميكية في المنظمات أدت إلى زيادة تأثيراتها السلبية تجاه البيئة، وهذا حدا بالقائمين عليها إلى احتواء هذه الظاهرة من خلال مجموعة مداخل منها (الإستراتيجية الخضراء)

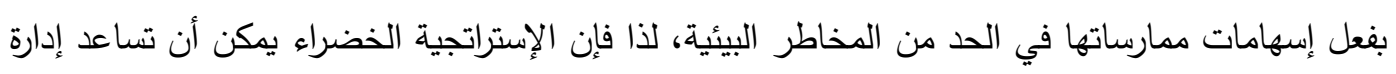
المنظمة على تحقيق الأفضلية على المنافسين، وبما يسهم في تحقيق متطلبات المسؤولية الاجتماعية والمساهمة في تعزيز التوجهات الإيجابية نحو البيئة.

ثالثاً - تطوير الإستراتيجية الخضراء على مستوى المنظمة

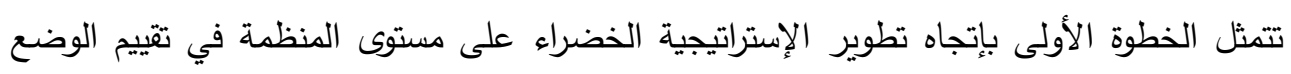

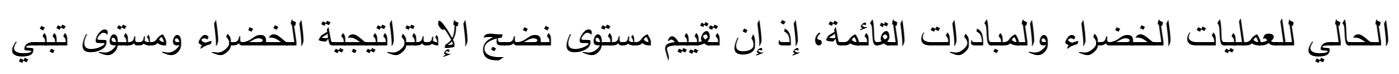

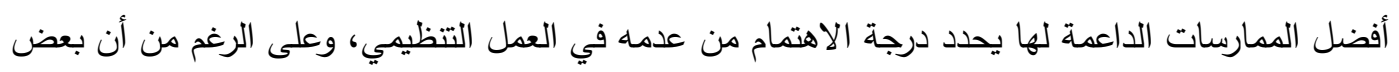

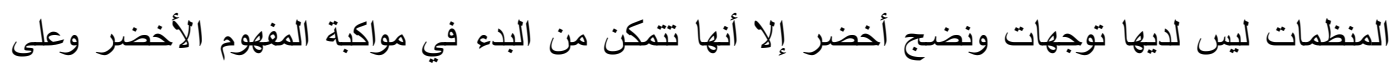

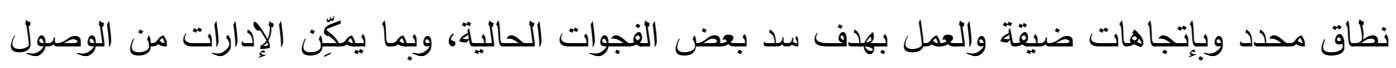
إلى التطلعات الخضراء ومواكبتها في بعض الأنشطة، وبما يمكنها أيضاً من التنافس مع المنظمات واتهات الأخرى

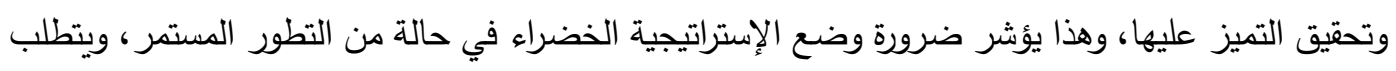
ذلك إتباع عدد من الخطوات يمكن الإشارة إليها من خلال الآتي: (Olson, 2009, 27-28) 1. التعريف: إذ يتوجب وضع الإرشادات وأهمية التغيير الثقافي والالتزام به وجعل الأولوية تجاه الممارسات

الخضراء. 
2. التطوير : دور القيادة في السعي نحو الاستثمارات الخضراء وتثجيع الموارد البشرية نحو استثمار الفرص وتتمية الإجراءات المعززة للتوجهات الخضراء وتخفيض مستويات الطاقة. 3. الممارسة: مزاوجة المبادئ الخضراء بالأعمال التقليدية والاهتمام بالتوجهات نحو الصناعة الخضراء وضرورة توافر قواعد مركزية خضراء. 4. الأنموذجية: وتتركز على التحسين المستمر والسياسات الداعمة للمبادرات بين الموارد البشرية والإستراتيجية والعمل على تعزيز النتائج وتطبيقها في أماكن متعددة في العمل.

رابعاً- متطلبات تنفيذ الإستراتيجية الخضراء تهذف المنظمات إلى تتفيذ الإستراتيجية الخضراء ضمن أعمالها ووظائفها، وهذه الإستراتيجية تتطلب توافر مجموعة من المتطلبات، وعلى النحو الآتي: (Al-Mawla, 2012, 43) 1. وضع أنظمة وتشريعات العمل المستمر لمراجعة الإجراءات وتحديث المعايير والمقاييس والإشادات الاتئ

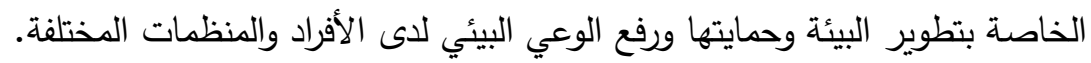

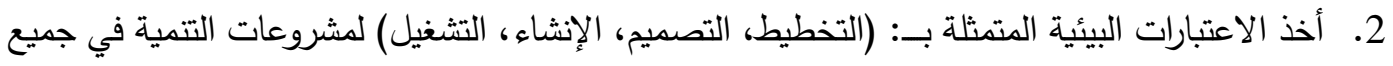
القطاعات، واستمرار مبدأ التقييم للآثار البيئية لأي نشاط تتموي.

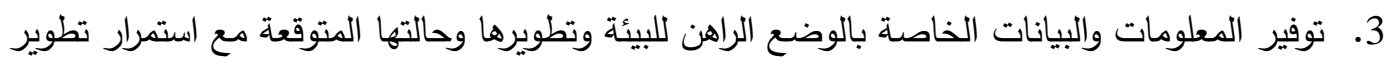
سبل رصد وتجميع وتبويب وعرض هذه البيانات والمعلومات.

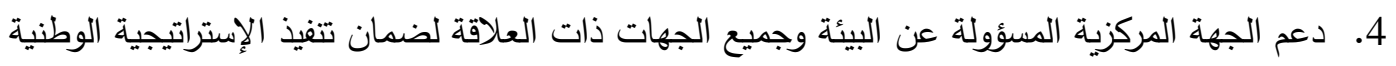

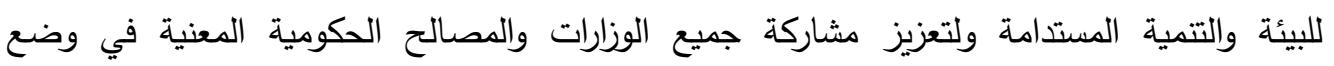
الإستراتيجية موضع التنفيذ. 5. توجيك فئات المجتمع وتعميق وعيها بالمشكلات البيئية التي تواجهها في حياتها اليومية وحثها على نهج سلوك جيد تجاه البيئة. 6. إلتزام أصحاب القرار بمراعاة الجانب البيئي في القرارات المتخذة.

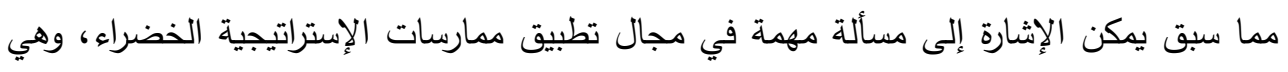
ضرورة توافر عدد من المتطلبات الداعمة لعملية التطبيق والتي يمكن أن تسهم في توجيه الإدارة في تتفيذها بطريقة كفوءة وفاعلة، وبما يمكنها من مواكبة المفهوم الأخضر وعلى قدر الإمكان.

خامساً- ممارسات الإستراتيجية الخضراء ازدادت اهتمامات المنظمات بأنشطة الإستراتيجية الخضراء بفعل زيادة الضغوط البيئية وزيادة مستويات التلوث واستهلاك الطاقة، وبدورها عدت الإستراتيجية الخضراء مطلباً للجميع ومصدراً للميزة التنافسية وتحقيق 
Kao, et (الأفضلية على المنافسين، ويمكن عرض ممارسات الإستراتيجية الخضراء وأنشطتها كما جاء بها فيما يأتي: al., 2008, 73 1. الثقافة الداخلية الخضراء والتي تركز على (أهمية وجود برامج التدريب والتعلم للعاملين فيما يخص حماية البيئة، وإدارة المواهب على نحو دوري، العمل على تكوين وحدات متخصصة فيها عاملين متدربين في هذا المجال، العمل على زيادة وعي العاملين تجاه حماية البيئة).

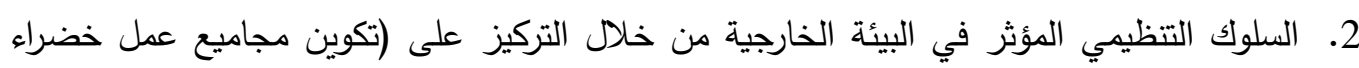

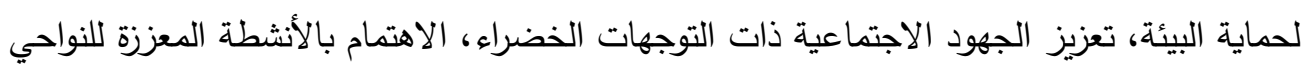

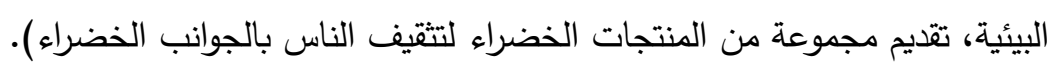

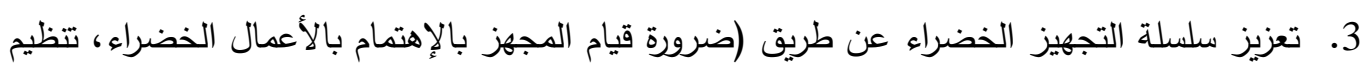
سلسلة التجهيز الخضراء، تحفيز العاملين في المستويات الإدارية كافة وبإسلوب تعاوني).

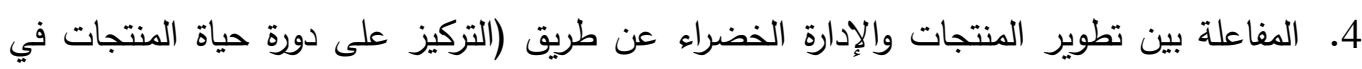
عملية التصميم، الاهتمام بتطبيق معايير المواصفة (ISO14001) ذات العلاقة بالبيئة، حماية البيئة بإتجاه تقييم السوق واستمرار تقديم المنتجات مع ضرورة تخفيض التكلفة). 5. الإمدادات الخضراء المعتمدة على المجهز عن طريق (إهتمام المنظمة بالتقليل من ظاهرة التلوث البيئي

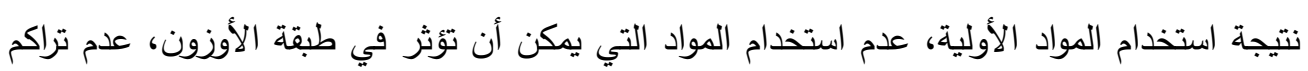

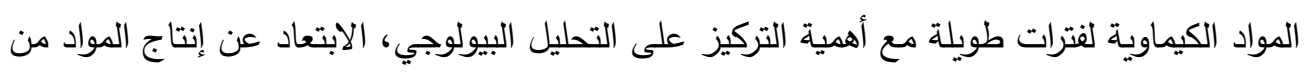
المصادر النادرة وذات القيمة). 6. تقليل استهلاك الطاقة المستخدمة بالتركيز على (استخدام الطاقة النظيفة، الإهتمام بالمعدات وتوفير

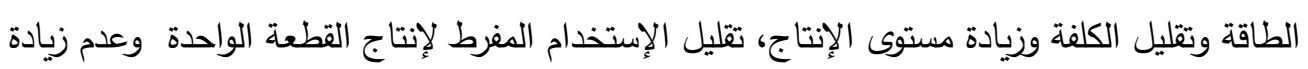

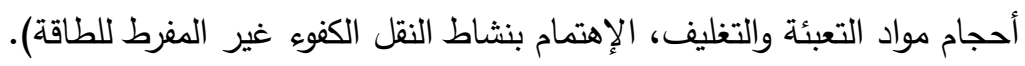
7. معالجة مخلفات العملية الإنتاجية عن طريق (وضع الآليات المناسبة لمعالجة مخلفات العمليات كالماء

$$
\text { والغازات وتخفيض كميتها، السيطرة المتحققة على التلوث البيئي). }
$$
8. تقديم الخدمات الخضراء بعد إستخدام المنتجات عن طريق (تقديم خدمات الإسترجاع، تجنب المواد الفعاد

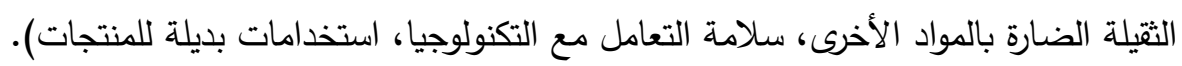
9. إعادة تدوير المنتجات ومعالجتها وهذا عن طريق (وجود أنظمة تمكن من إعادة المواد، بساطة التصميم لتحقيق مبدأ السهولة، استخدام التكنولوجيا المساعدة على إعادة المنتجات).

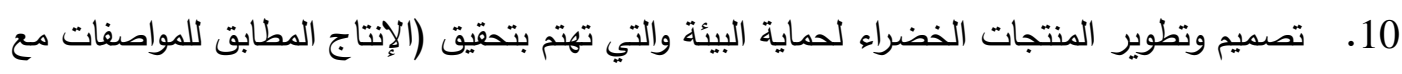
تطوير الطاقة المستدامة والممارسة كطاقة الريح والطاقة الثمسية، تعزيز مستوى التطبيق العلمي للمنتجات والخدمات، التصنيع الأخضر الذي يقلل من مستوى التلوث). 
11. تصميم المنتجات الخضراء الموجهة للزبون عن طريق (سهولة ممارسة أجزاء من المنتجات، تقليل الطلب على الطاقة، استخدام الموارد الديناميكية، تصميم المنتجات المتعددة الوظائف، إطالة مدة حياة المنتجات، تقليل مستوى الخطأ عند الاستخدام من قبل الزبون).

يمكن عرض الإطار الميداني للبحث الحالي عن طريق تأشير المضامين الآتية: أولاًَ- وصف الأفراد المبحوثين

قد وجهت أداة البحث على عينة من الأفراد المبحوثين في المنظمة المبحوثة، إذ تم توزيع (118) إستمارة إستبانة، استعيد منها (103) إستمارة إستبانة صالحة للتحليل الإحصائي وبنسبة (87\%)، والجدول 2 يعكس وصفاً دقيقاً للأفراد المبحوثين في المنظمة المبحوثة، وعلى النحو الآتي:

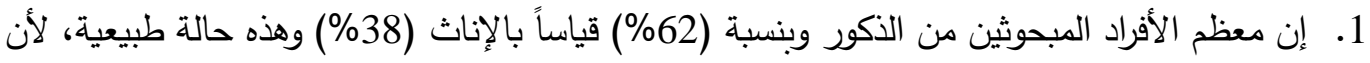

هذا النوع من المنظمات يتطلب مجهودات عالية، وهذا ما متوافر لدى الذكور في العمل.

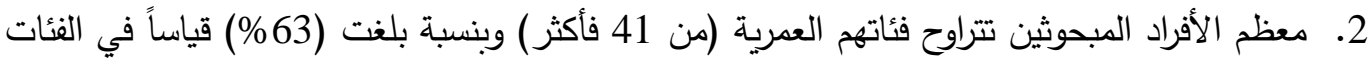
العمرية الأخرى، وهذا يعكس مدى خبرتهم في العمل التنظيمي.

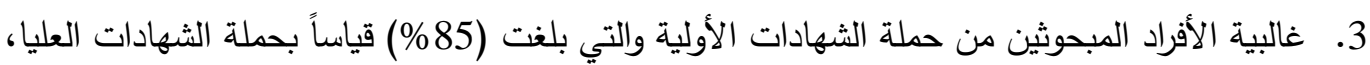
وهذا يؤشر انخفاضاً في عدد الأفراد العاملين من ذوي الثهادات العليا.

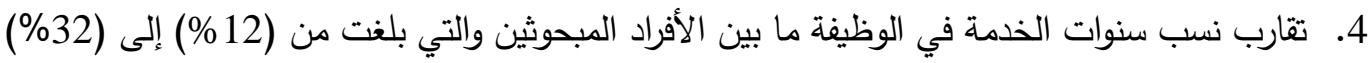
وهذا يؤكد صحة التوزيع النسبي للأفراد المبحوثين من حيث سنوات الخدمة في الوظيفة.

جدول (2): وصف الأفراد المبحوثين

\begin{tabular}{|c|c|c|c|c|c|}
\hline \multicolumn{6}{|c|}{ الجنس } \\
\hline \multicolumn{3}{|c|}{ أنثى } & \multicolumn{3}{|c|}{ ذكر } \\
\hline \multicolumn{3}{|c|}{$\% 38$} & \multicolumn{3}{|c|}{$\% 62$} \\
\hline \multicolumn{6}{|c|}{ العمر } \\
\hline $\begin{array}{c}------ \\
--\end{array}$ & 61 سنة فأكثر & من 51 إلى 61 & من 41 إلى 50 & من 31 إلى 40 & 30 سنة فأقل \\
\hline $\begin{array}{c}------ \\
--\end{array}$ & $\% 7$ & $\% 16$ & $\% 40$ & $\% 24$ & $\% 14$ \\
\hline \multicolumn{6}{|c|}{ المؤهل العلمي } \\
\hline إعدادية & دبلوم فني & بكالوريوس & دبلوم عالٍ & ماجستير & دكتوراه \\
\hline$\% 11$ & $\% 15$ & $\% 59$ & $\% 7$ & $\% 9$ & $\% 0$ \\
\hline
\end{tabular}




\begin{tabular}{|c|c|c|c|c|c|}
\hline \multicolumn{6}{|c|}{ سنوات الخدمة في الوظيفة } \\
\hline $\begin{array}{c}------ \\
--\end{array}$ & 21 سنة فأكثر & من 16 إلى 20 & من 11 إلى 15 & من 6 إلى 10 & 5 فنقوات 5 فأقل \\
\hline $\begin{array}{c}------ \\
--\end{array}$ & $16 \%$ & $\% 20$ & $\% 32$ & $\% 20$ & $\% 12$ \\
\hline
\end{tabular}

المصدر : الجدول من إعداد الباحثة.

ثانياً- المقاييس الوصفية لإجابات الأفراد المبحوثين في المنظمة المبحوثة

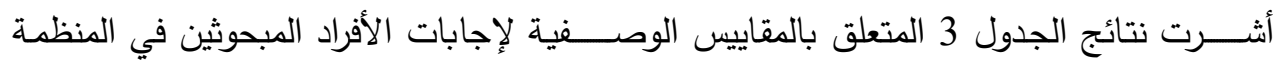

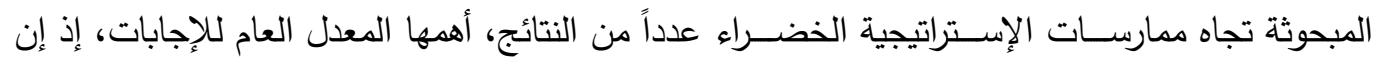

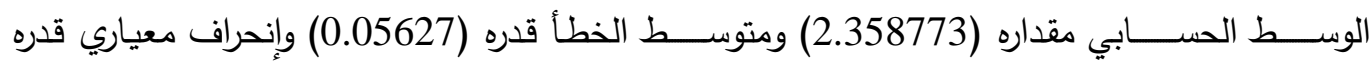

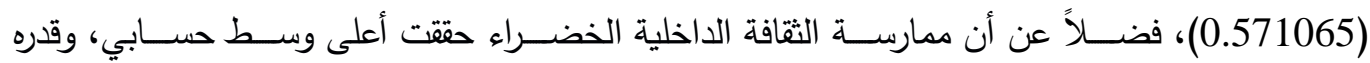
(2.5461) وبمتوســـ الخطأ (0.05462) وانحراف معياري (0.55434)، كما إن ممارســـة إعادة تدوير

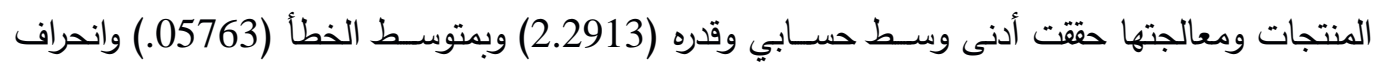
معياري (58483.)، في حين حقتت الممارسات الأخرى حالة من الوسطية بين تلك الممارستين.

جدول (3): المقاييس الوصفية لعينة البحث في المنظمة المبحوثة

\begin{tabular}{|c|c|c|c|c|c|}
\hline المعياري الانحراف & متوسط الخطأ & الكسابي & 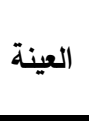 & 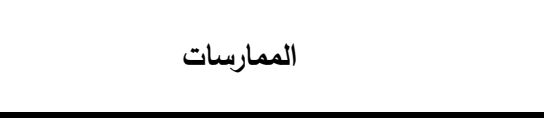 & $ت$ \\
\hline 0.55434 & 0.05462 & 2.5461 & 103 & الثقافة الداخلية الخضراء & .1 \\
\hline 0.55950 & 0.05513 & 2.3519 & 103 & السلوك التتظيمي المؤثر في البيئة الخارجية & .2 \\
\hline 0.61333 & 0.06043 & 2.4345 & 103 & تعزيز سلسلة التجهيز الخضراء & .3 \\
\hline 0.53990 & 0.05320 & 2.3398 & 103 & المفاعلة بين تطوير المنتجات والإدارة الخضراء & .4 \\
\hline 0.62301 & 0.06139 & 2.3131 & 103 & الإمدادات الخضراء المعتدة على المجهز & .5 \\
\hline 0.54457 & 0.05366 & 2.3422 & 103 & تقليل استهلاك الطاقة المستخدمة & .6 \\
\hline 0.58559 & 0.05770 & 2.3835 & 103 & معالجة مخلفات العملية الإنتاجية & .7 \\
\hline 0.55688 & 0.05487 & 2.2985 & 103 & تقديم الخدمات الخضراء بعد استخدام المنتجات & .8 \\
\hline 0.58483 & 0.05763 & 2.2913 & 103 & إعادة تدوير المنتجات ومعالجتها & .9 \\
\hline 0.55350 & 0.05454 & 2.3422 & 103 & تصميم وتطوير المنتجات الخضراء لحماية البيئة & .10 \\
\hline 0.56626 & 0.05580 & 2.3034 & 103 & تصميم الكنتجات الخضراء الموجهة للإنسان & .11 \\
\hline 0.571065 & 0.05627 & 2.358773 & 103 & 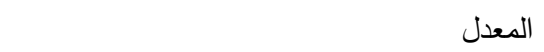 & .12 \\
\hline
\end{tabular}

المصدر : الجدول من إعداد الباحثة بالاعتماد على برنامج (SPSS). 
ثالثاً- إختبار (Friedman) لإجابات الأفراد المبحوثين في المنظمة المبحوثة يســتخدم (Friedman Test) لتحديد مدى وجود فروق معنوية ذات دلالة إحصــــائية بين ثلاث

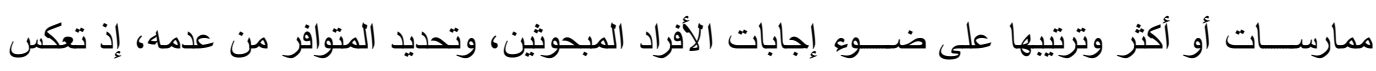

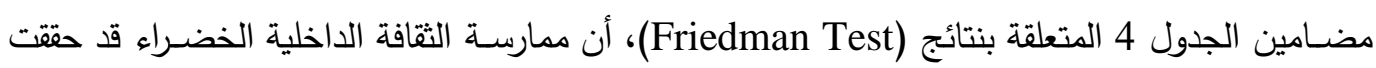
أعلى متوسط للرتب بمستوى (6.99) ليكون في المرتبة الأولى، أما ممارسة تعزيز سلسلة التجهيز الخضراء التهاء

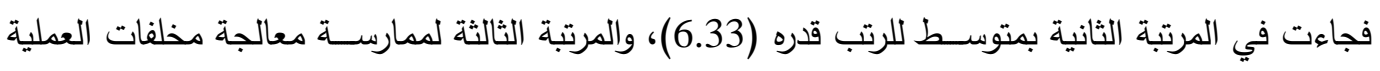

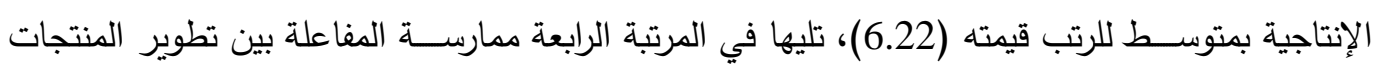

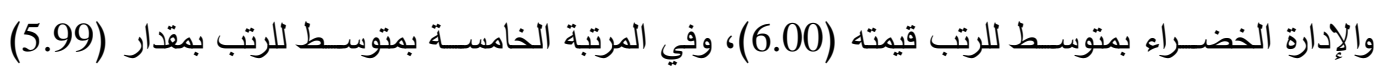

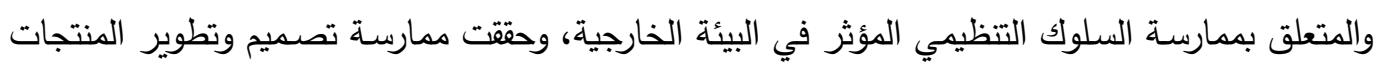

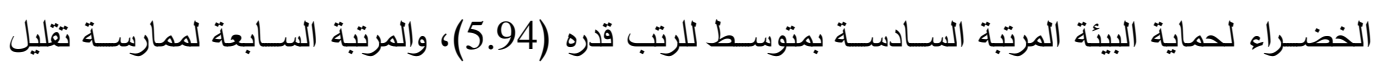

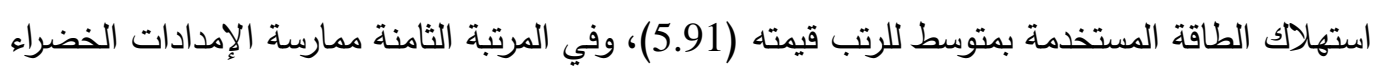

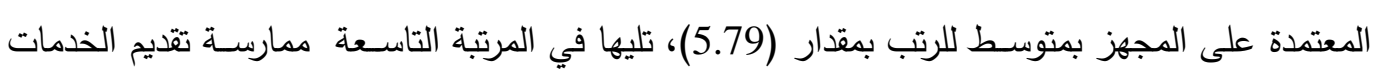

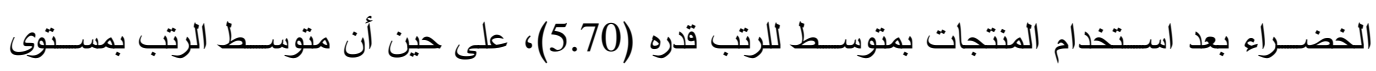

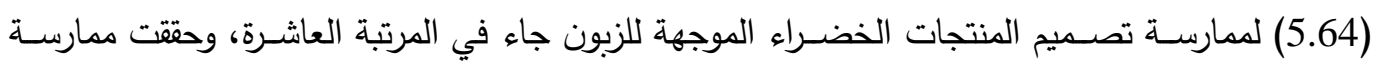

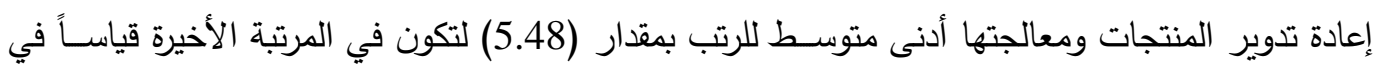

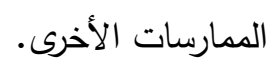

خلاصــــة لما تم تقديمه في (Friedman Test) أن قيمة (Friedman) أي (Chi-Square) حققت (19.168) عند درجة حرية (Df) بلغت (10)، وإن متوســـ الدلالة الإحصــائية لإجابات الأفراد المبحوثين في المنظمة المبحوثة (Sig. Asymptotique) بلغت قيمتها (0.038) وهذه القيمة هي أقل

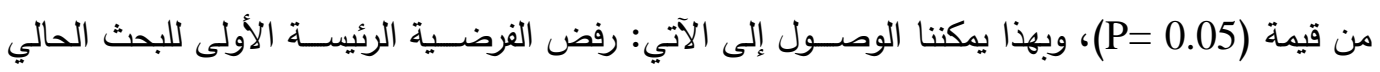

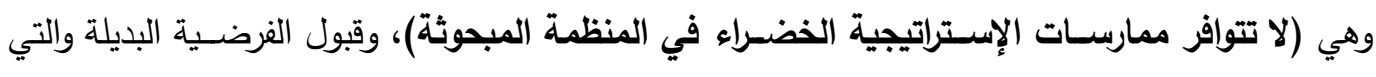

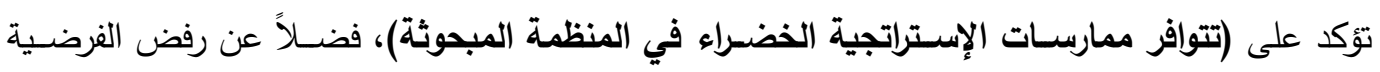

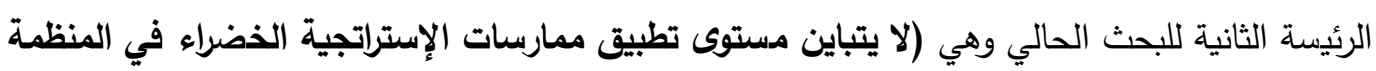

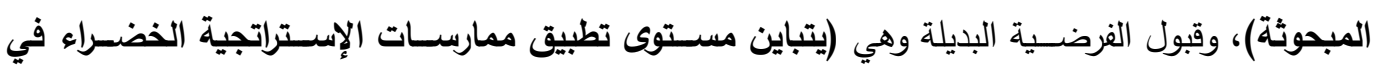

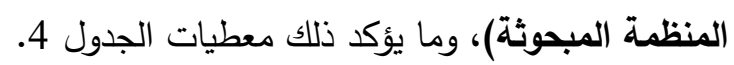

جدول (4): إختبار (Friedman) لإجابات الأفراد المبحوثين في المنظمة المبحوثة

\begin{tabular}{|c|c|c|c|}
\hline الترتيب & $\begin{array}{c}\text { Mean Rank } \\
\text { متوسط الرتب }\end{array}$ & الممارسات & ت \\
\hline 1 & 6.99 & الثقافة الداخلية الخضراء & .1 \\
\hline 5 & 5.99 & السلوك التنظيمي المؤثر في البيئة الخارجية & .2 \\
\hline
\end{tabular}

TANMIYAT AL-RAFIDAIN (P-ISSN: 1609-591X; E-ISSN: 2664-276X) تنمية الرافدين 
ممارسات الإستراتيجية الخضراء باستخدام نموذج (Kao)

الملاتوحي

\begin{tabular}{|c|c|c|c|}
\hline الترتيب & $\begin{array}{c}\text { Mean Rank } \\
\text { متوسط الرتب }\end{array}$ & الممارسات & 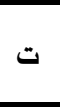 \\
\hline 2 & 6.33 & تعزيز سلسلة التجهيز الخضراء & .3 \\
\hline 4 & 6.00 & المفاعلة بين تطوير المنتجات والإدارة الخضراء & .4 \\
\hline 8 & 5.79 & الإمدادات الخضراء المعتمدة على المجهز & .5 \\
\hline 7 & 5.91 & تقليل استهلاك الطاقة المستخدمة & .6 \\
\hline 3 & 6.22 & معالجة مخلفات العملية الإنتاجية & .7 \\
\hline 9 & 5.70 & تقديم الخدمات الخضراء بعد إستخدام المنتجات & .8 \\
\hline 11 & 5.48 & إعادة تدوير المنتجات ومعالجتها & .9 \\
\hline 6 & 5.94 & تصميم وتطوير المنتجات الخضراء لحماية البيئة & .10 \\
\hline 10 & 5.64 & تصميم المنتجات الخضراء الموجهة للزبون & .11 \\
\hline
\end{tabular}

المصدر : الجدول من إعداد الباحثة بالاعتماد على برنامج (SPSS).

\begin{tabular}{|c|c|c|}
\hline \multicolumn{3}{|c|}{ Test Statistics ${ }^{\mathbf{a}}$} \\
\hline $\mathbf{N}$ & العينة & 103 \\
\hline Chi-Square & قيمة Friedman & 19.168 \\
\hline Df & درجة الحرية & 10 \\
\hline Sig. Asymptotique & مستوى الدلالة الإحصائية & 0.038 \\
\hline
\end{tabular}

$$
\text { المحور الرابع - الإستنتاجات والمقترحات }
$$

بهدف إتمام البحث الحالي من حيث التغطية المنهجية والنظرية والميدانية لا بد من تقديم مجموعة

من الإستتتاجات والمقترحات، وبما يمكن أن يسهم في توجيه المنظمة المبحوثة نحو واقع تطبيق ممارسات الإستراتيجية الخضراء ومن ثم توعيتها بخصوص معالجة السلبيات وتعزيزها للممارسات الإيجابية وعلى قدر

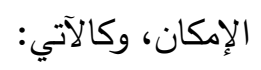

$$
\text { أولاًَ- الإستتتاجات }
$$

بالاعتماد على ما تمخض عنه المحور النظري والميداني يمكن عرض أبرز الإستنتاجات التي تم

$$
\text { التوصل إليها، وعلى النحو الآتي: }
$$

1. وجود حالة من الإتفاق بشأن توافر ممارسات الإستراتيجية الخضراء في المنظمة المبحوثة وبمستوى متباين بين ممارسة وأخرى. 
2. إهتمام ملحوظ من قبل إدارة المنظمة المبحوثة بثأن الثقافة الداخلية ذات التوجهات الخضراء من حيث

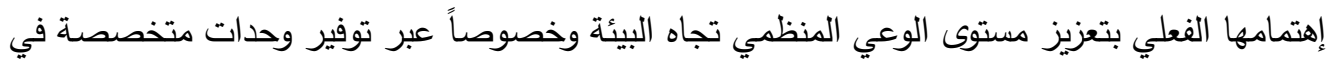

$$
\text { ذلك وتدريب العاملين. }
$$

3. تعتمد المنظمة المبحوثة في عملياتها على سلسلة التجهيز ذات الومضة الخضراء عن طريق توجيه

المجهز بذلك والتتظيم الجيد لها، وبما يمكنها من خدمة الزبون بالمنتجات والخدمات الخضراء.

4. تتوافر أفضل الأساليب التي تمكن المنظمة المبحوثة من معالجة مخلفات العملية الإنتاجية من خلال

التزكيز على توفير وسائل نقلها، فضلاً عن السيطرة على المخلفات الصلبة والسائلة والغازية.

5. تهتم المنظمة المبحوثة بالجوانب الخضراء عند تصديم المنتجات من خلال توفيرها متطلبات

(ISO14001) ذات العلاقة بالبيئة، وهذا يتحقق من خلال تعاون جميع أطراف العمل.

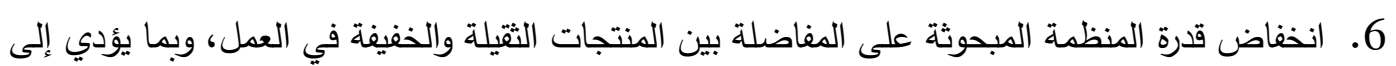
ضعف توافر الاستخدامات البديلة للمنتجات.

7. ضعف ملحوظ في ممارسة إعادة تدوير المنتجات ومعالجتها، ومرد ذلك تعقيد الأساليب المتبعة في إعادة

تدوير المنتجات ومعالجتها، فضلاً عن عدم وجود الوحدات المتخصصة في هذه العملية.

$$
\text { ثانياً- المقترحات }
$$

توصل البحث إلى مجموعة من المقترحات بالاعتماد على الاستتاجات التي تم تقديمها، وهي على

$$
\text { النحو الآتي: }
$$

1. ضــــرورة زيـادة الاهتمـام الفعلي من قبل الإدارة بالنواحي الـاعمـة للتوجهات البيئيـة وتحديداً عبر

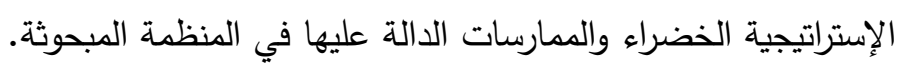

2. الإهتمام الفعلي بتعزيز مستوى ممارسات الإستراتيجية الخضراء في المنظمة المبحوثة في إطار مواكبة

$$
\text { التغيير والتطوير الملحوظين وبالذات ما يتعلق بالتوجه البيئي. }
$$

3. تفعيل مداخل الوعي المنظمي لتعزيز مسـتوى توجهات الأفراد العاملين نحو التقليل من مسـتوى التلوث

$$
\text { وحماية البيئة في إطار الومضات الخضراء، وبما يسهم في تحقيق الأهداف. }
$$

4. السعي نحو توفير أفضل الأساليب المكنة بخصوص عملية الفصل بين المنتجات الثقيلة والخفيفة في

$$
\text { العمل، وبما يمكن من استخدامها في إطار الإستدامة. }
$$

5. توفير مجموعة من الاستخدامات البديلة للمنتجات والتي تسهم في تحقيق أهم متطلبات التتمية المستدامة ونة

وبالذات الداعمة للتوجهات البيئية.

6. أهمية توافر وحدات عمل متخصصة في المنظمة المبحوثة تكون مهمتها إعادة تدوير المنتجات ومعالجتها، وهذا من خلال إستقطاب أفضل الموارد البشرية، ومن ثم تدريبهم لتحقيق الأهداف. 


$$
\begin{aligned}
& \text { 7. ضرورة استخدام التكنولوجيا الحديثة في عملية إعادة تدوير المنتجات ومعالجتها، وبما يحقق بساطة } \\
& \text { الأساليب المستخدمة في العمل، ومعالجة حالة التعقيد في العمل التظظيمي. }
\end{aligned}
$$

\section{References}

Al-Abedi, Ali Razak Jiyad \& Al-Jubouri, Qasim Hadi Azouz, (2017), Sustainability-Oriented Strategies and its Role in the Organizational Development for Najaf Province Governorate, AL Gharee for Economics and Administration Sciences, Vol. (14). No. (2).

Al-Anzi, Saad Ali Hamoud \& Al-Khafaji, Raed Rahim Muhammad, (2017), The Require ments of the Strategy Trans formation Toward Green City. The Develop OF Local in Hilla City Asacase Study, The Administration \& Economic College Journal For Economics \& Administration \& Financial Studies, Vol. (9). No. (1). Al-Mawla, Omar Salem Aziz, (2012), Green Strategy Processes and its Role in Enhancing Strategic Corporate Social Responsibility: Case Study In General Company of Drugs and Appliances Industry/ Nineveh, Master's Thesis, College of Administration and Economics, University of Mosul, Iraq.

Ayoubi, Maryam, Mehrabanfar, Ehsan \& Banaitis, Audrius, (2017), Guidelines on Designing Conceptual Framework for Strategic Management with Application to the Energy Industry, Adm. Sci, Vol. (8), No. (27).

Burgelman, Robert A., et al., (2017), Strategy processes and practices: Dialogues and intersections, John Wiley \& Sons, Vol (13).

Düren, Zeynep \& Yılma, İlkus, (2010), The Role of Creen Busıness Strategies on Sustaining Competitive Advantage, EVL Journal of Social Sciences, (I: i).

Fousteris, Andreas E., at al., (2018), The Environmental Strategy of Businesses as an Option under Recession in Greece, Sustainability.

Huiru, Ding, (2011), The Importance of Strategic Management: A case study of H\&M, Business and Administration, Kuopio.

Genc, Elif, (2017), Strategy Implementation, Organizational Culture and Performance in Turkish Local Government, Thesis of Doctor, Cardiff Business School, Cardiff University.

Gweh, Bonekeh Belidus, (2018), The Impact of Strategic Management on The Growth of SMEs, Thesis, Centria University of Applied Sciences International Business Administration.

Mainardes, Emerson Wagner, Ferreira, João J.\& Raposo, Mario L,(2014), Strategy and Strategic Management Concepts: Ary They Recognised By Management Students, Business Administration and Management.

TANMIYAT AL-RAFIDAIN (P-ISSN: 1609-591X; E-ISSN: 2664-276X) تنمية الرافدين 
Masoumik, Maryam S., at al., (2015), Importance-Performance Analysis of Green Strategy Adoption within the Malaysian Manufacturing Industry, Elsevier B.V.

Olson, Eric G., (2009), Creating an enterprise-level "green" Strategy, Journal of Business Strategy, Vol. (29), No. (2).

Kao, Ghi Hwei, Liu, huo Fang \& Chu, Che Ching, (2008), Raising Corporate Social Responsibility By Green Strategy, Yadong Xuebao, No. (28).

Karagülle, Ali Özgür, (2012),Green business for sustainable development and competitiveness: an overview of Turkish logistics industry, The First International Conference on Leadership, Technology and Innovation Management.

Loknath Y. \& Azeem, Abdul B., (2017), Green Management -Concept and Strategies, National Conference on Marketing and Sustainable Development.

Padash, A., at al., (2015), Green strategy management framework towards sustainable development, Bulgarian Cshemical Communications, Vol. (47), Issue. (D).

Saeed, Sanaa Abdul Rahim, (2013), The Requirements of Achieving Sustainable Competitive Advantage under Framework of Constructing Green Strategy for Business Organizations ( perceptual analytical study), Journal of Economic and Administrative Sciences, Vol. (19). No. (73).

Sawant, Siddhant Umesh, at al., (2013), Strategy for Implementation of Green Management System to Achieve Sustainable Improvement for Eco friendly Environment, Globally, International Journal of Innovative Research in Science, Engineering and Technology, Vol. (2), Issue (10).

Sergio, Jofre, (2019), Strategic Management: The theory and practice of strategy in (business) organizations, Department of Management Engineering. 